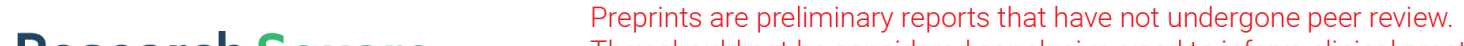 They should not be considered conclusive, used to inform clinical practice, or referenced by the media as validated information. \\ Estimation of Autophagy Activity By Evaluating Possible MicroRNA Biomarkers and FOX01 mRNA Level in Papillary Thyroid Carcinoma
}

\section{Mojtaba Zehtabi}

Tabriz University of Medical Sciences Faculty of Medicine

Amir Mahdi Khamnei ( $\square$ khamaneh@tbzmed.ac.ir)

Tabriz University of Medical Sciences Faculty of Medicine

\section{Siamak Salehi}

King's College Hospital NHS Trust: King's College Hospital NHS Foundation Trust

\section{Zahra Akbarpour}

Azad University: Islamic Azad University

\section{Yousef Roosta}

Urmia University of Medical Sciences

\section{Sepehr Valizadeh}

Tabriz University of Medical Sciences

\section{Mortaza Raeisi}

Tabriz University of Medical Sciences https://orcid.org/0000-0002-3173-1610

\section{Research Article}

Keywords: Papillary Thyroid Carcinoma, Autophagy, mRNA, miRNA

Posted Date: August 20th, 2021

DOl: https://doi.org/10.21203/rs.3.rs-802917/v1

License: (9) This work is licensed under a Creative Commons Attribution 4.0 International License. Read Full License 


\section{Abstract}

Background: Papillary thyroid carcinoma (PTC) is the most prevalent endocrine malignancy. Despite nearly three-fold increase in incidence over three decades, the mortality rate remains unchanged. Biomarkers related to early diagnosis and prognosis of PTC are poorly investigated. Autophagy pathways and related miRNAs is considered to play an important role in PTC pathophysiology.

Methods and Results: Tissue samples from patients with PTC undergoing thyroidectomy were collected. Total RNA content of tumor and margin samples were purified and converted to cDNA. Gene expression levels of mRNA (FOXO1) and miRNAs (miR-30d-5p, miR-182-5p and miR-183-5p) were evaluated using qPCR method in PTC and adjacent normal tissue. A 6.51-fold decrease in miR-30d-5p level was detected in tumor samples compared to adjacent tissues. Moreover, miR-182-5p and miR-183-5p (FOXO1 as the main target) showed 1.73- and 4.31-fold increases in their levels, respectively. We also observed a 2.66fold decrease in FOXO1 mRNA level in relation to these miRNA fold changes indicating a possible correlation between autophagy-linked molecular events and PTC.

Conclusions: Significant increase in miR-183-5p and miR-182-5p expression, as well as a decrease in FOX01 and miR-30d-5p expression, suggest that PTC has active autophagy machinery. This can possibly be used as a novel diagnostic or prognostic biomarker.

\section{Introduction}

The thyroid gland is a shield-shaped endocrine organ that displays a high malignancy rate in the human population. Thyroid cancer incidence has been increased over recent decades [1]. Almost all thyroid cancers are driven from follicular epithelium which has three major subtypes: papillary thyroid carcinoma (PTC), follicular, anaplastic and some other rare types of which the PTC is the most common [2, 3]. There is a wide range of predisposing or risk factors from environment to genetics. The incidence of PTC has increased recently in parallel with other types and there is potential to become a health concern in near future. This can be fueled by an increase in risk factors prevalence or recent advances in diagnostic tools $[4,5]$.

Fine needle aspiration (FNA) is the gold standard to screen suspicious thyroid lesions but negative results remain a concern. Although FNA is a most commonly used test, but clinical findings should overrule FNA results $[6,7]$. Not only genetic and molecular variations are playing some parts in PTC development and prognosis, but also can be utilized as an early screening tools [8]. Despite the recent advances in molecular diagnostic tests and lack of reliable biomarkers, there are no accurate and efficient molecular biomarkers available for early detection of PTC $[8,9]$.

Autophagy is a relatively well-known and highly conserved process in eukaryotes in which intracellular components are degraded to maintain cellular homeostasis. Various human diseases are suspected to be correlated with impaired autophagy like cancers $[10,11]$. There are three primary types of autophagy: macroautophagy, microautophagy, and chaperone-mediated autophagy. The Macroautophagy is much 
more defined compared to other types, thus in the rest of this article, the autography term refers to the macro-autophagy type only [11]. Autophagy is a potent anti-tumorigenic mechanistic in normal noncancerous cells which compensates oxidative stress by eliminating oxidants and preventing DNA damage [12]. But on the contrary, entirely fitted cancerous cells, employ autophagy to survive and propagate in the unfavorable tumor microenvironment. Furthermore, autophagy regulates the properties of cancer stem cells leading to recurrence and resistance to anticancer agents. Some synthetic autophagy modulators such as rapamycin and chloroquine, are used to regulate autophagy in cancer treatment trials. However, many studies have shown that autophagy plays role in both tumor suppression and activation of oncogenes $[12,13]$. Although autophagy plays a role in tumor suppression pathways in PTC but it can improve the cell survival in tumor progression, influence distant metastasis, and causes resistance to therapeutic agents $[14,15]$.

FOXO1 is a member of the forkhead box $\mathrm{O}$ (FOXO) family which acts as a transcription factor with a critical role in many cellular processes including apoptosis and autophagy. FOXO1 functions as a convergence gene in the autophagy pathway (KEGGmap04068) [16,17], and its expression is downregulated in PTC and classified as a potential tumor suppressor [18].

MicroRNAs (miRNAs) are short, non-coding RNAs with a post-transcriptional effect on mRNAs. MicroRNAs have been shown to possess a wide variety of effects in cellular events and diseases [19,20]. Many studies have demonstrated that miRNA dysregulation is related to cancer behavior through various mechanisms, including inflammation, cell cycle regulation, evading growth suppressors, resisting cell death, activating invasion and metastasis, and inducing angiogenesis [21]. So a general or specific miRNA profile patterns could be considered in different cancers. In this regard, remarkable miRNA up-anddown- regulation is correlated with PTC clinical features. (e.g. miR-199b-5p expression could predict lymph node metastasis) [20,21]. An experimental study on Ishikawa cell line which are well-differentiated endometrial cancer cells demonstrated significant negative correlation between miR-182-5p and miR-183$5 p$ with FOXO1 proposing the hypothesis that this correlation may be present in other well-differentiated cancer types like PTC [22].

The term "oncomir" is referred to miRNAs which are found in abundance within cancerous tissues and can act as oncogenes or repress tumor suppressor mRNAs regardless of their effect on the behavior and prognosis of tumors. miR-30d-5p is an oncomir that regulates autophagy in cancer cells by targeting multiple autophagy-related genes like Beclin-1 $[23,24]$ and potentially can be considered as an autophagy function index. Recently, the circulating miRNAs in patients' serum are considered as potential biomarkers for early diagnosis of PTC which are able to discriminate benign nodules from malignant ones [25].

In this study, we assessed the FOX01 mRNA expression level and miRNAs related to autophagy machinery in PTC tumors (miR-30d, miR-182-5p, and miR-183-5p). We aim to identify the role of these miRNAs and FOXO1 in autophagy status in PTC progression and elucidate the possible screening value of these modalities in PTC pathophysiology and prognosis. 


\section{Materials And Methods}

\section{Data Collection}

The sample collection of this study was performed between March 2017 and July 2018 in Imam Reza hospital, Tabriz, Iran. Cytopathology reports of all patients who had undergone fine needle aspiration (FNA) from outpatient endocrinology clinic between March 2017 and July 2018 were analyzed, 40 samples with a definite diagnosis of PTC and 40 control samples from non-cancerous adjacent tissue of same patient were selected.

In this study, the control non-cancerous tissues is confirmed by H\&M staining followed by microscopic evaluation. The experimental procedures described below, was performed in molecular laboratory setting in December 2020 at Nemooneh Medical Laboratory, Tabriz, Iran.

The exclusion criteria of our study were history of other thyroid diseases (due to the potential role of disrupted autophagy), previous chemotherapy or radiotherapy and diagnosis of other simultaneous malignancies.

\section{Patient and Samples Information}

This retrospective study excluded patients who had comorbid disorders, history of malignancy, contraindications for FNA and a family history of thyroid cancers.

Thyroid surgery samples including tumor and non-transformed adjacent tissues were obtained and underwent routine tissue collection procedure. After rinsing with normal saline, they were transferred to cryotubes and immediately preserved in a liquid nitrogen tank, then all samples were transferred to -70 degree freezer.

\section{RNA Extraction}

Trizol reagent was used to extract total RNA (Ambion life technologies, UK). The key components of this reagent are guanidiniumthiocyanate and phenol, which denature proteins and prevent RNase's unwanted effects on RNA material.

To extract total RNA, $300 \mathrm{mg}$ of tissue was grinded using a porcelain mortar and pestle under liquid nirtrogen, homogenized tissue was transferred to $700 \mathrm{ul}$ Trizol reagent directly in a microtube. The procedure followed by adding 200ul chloroform and centrifugation according to the manufacturer protocol (MAN0001271). The upper aqueous phase was transferred to a new microtube, total RNA purified by adding isopropyl alcohol, absolute ethanol, and $70 \%$ ethanol serially, separating by centrifugation steps. Purified RNA ( $\mathrm{ng} / \mathrm{ul}$ ) quantity and possible protein or mineral residue contamination (extract quality) evaluated by Nanodrop device (Spectrophotometer 2000/2000c).

\section{cDNA Synthesis}


Two micrograms of purified mRNA was converted into cDNA by Moloney Murine Leukemia Virus Reverse Transcriptase (M-MLV) in the 5Xbuffer, dNTP, and random hexamer primers, according to the manufacturer protocol (Lot N:cs0025). Steps installed for specific miRNAs and housekeeping miRNA by stem-loop technology, Biomir high sensitivity microRNA kit (Zistroyesh. Co).

\section{Quantitative Real-Time PCR}

To define the expression levels of genes, the quantitative Real-Time PCR (qPCR) technique was used. Gene-specific primer mix with PCR Master of Hot Start Taq DNA Polymerase and SYBR green was used for each gene (AnaCell).

The fluorescence emission variation of each gene in QPCR assay matched the quantity of mRNA or miRNA fragments in the sample $\mathrm{Ct}$ (cycling time) values in results that point on the qPCR curve which cuts off the threshold line.

qPCR amplifications program includes an initial 15 minute hold at $95^{\circ}$ to trigger the Hot Star Taq Master Mix Taq polymerase followed by 20 seconds at $95^{\circ}$ and an annealing-extension step of 60 seconds at $60^{\circ}$ for $35-40$ cycles with a final melt analysis step of $55^{\circ}-95^{\circ}$.

\section{Data Analysis}

In this study, we tried to determine miR-182-5p, miR-183-5p, and miR-30d-5p as potential biomarkers in autophagy so our attempt to measure FOXO1 mRNA was considered as the extrinsic goal. To optimize data reproducibility, all tests were performed in triplicate format and normalized by efficiency index.

Evaluating and analyzing $\mathrm{Ct}$ data has been done by the $\Delta \Delta \mathrm{Ct}$ method, first $\mathrm{Ct}$ data (Ct target gene-Ct ref housekeeping gene; treated sample)-(Ct target gene- $\mathrm{Ct}$ ref gene; untreated control) - the resulting $\triangle \Delta \mathrm{CT}$ value be used as the exponent of power $2 ;\left(2^{\wedge}-\Delta \Delta C t\right)$ which is a conventional method for the expression value fold change variation [26]. Ct values were used to compare target and reference genes expression levels and fold changes were the reflection of a relative quantification.

\section{Results}

\section{Clinical Findings}

After excluding the patients who met the exclusion criteria, the general information about the 40 patients who participated our research was analyzed as shown in Table 1.

\section{Main Findings}

We evaluated the expression of FOX01 gene mRNA, miR-182-5p, miR-183-5p and miR-30d-5p in PTC and non-cancerous normal adjacent tissue. The information demonstrating the expression levels of foresaid molecules is mentioned below and is summarized in Table 2 . 
Inducible FOX01-dependent autophagy is one of the various cellular functions regulated by the FOXO signaling pathway which itself is over-activated by upstream signals stimuli leads to acetylated activation of the FOXO1 transcription factor in PTC patients, however it needs more mechanistic studies to determine pragmatic correlation between FOXO1 and autophagy [27].

In our samples, the evaluation of FOX01 expression levels in PTC and non-tumoral adjacent tissue demonstrated that this gene's expression is 2.66 -fold decreased in PTC compared to adjacent normal tissue. This outcome is considered significant and is shown in figure $1(t=4.849, \mathrm{df}=53, \mathrm{PTC}$ Mean $\pm \mathrm{SD}=$ $-0.3767 \pm 1.36$, control Mean $\pm S D=1.418 \pm 1.373$, P-value $<0.0001)$.

\section{miR-182-5p}

MicroRNA-182-5p targets FOX01 demonstrated in neoplastic tissue which is associated with rapidly growing and more invasive states $[22,28]$. The prediction score of repressing FOXO1 by miR-182-5p has been calculated as 0.821 out of 1 [29].

In our study, and as demonstrated in figure 2, assessing the levels of miR-182-5p in PTC and noncancerous tissue depicted a significant finding of 1.73-fold increase in expression in the PTC tissue. $(t=2.809, d f=52, P T C$ Mean $\pm S D=-9.136 \pm 1.201$, control Mean $\pm S D=-10.14 \pm 1.414, P-$ value $=0.007)$.

\section{miR-183-5p}

The inhibitory effect of miR-183-5p on FOXO1 has been shown in previous studies, rendering the tumor high proliferative state $[22,28,30]$. The prediction score of repressing FOXO1 by miR-183-5p has been calculated as 0.783 out of 1 [29].

As displayed in figure 3, our examination on PTC and adjacent non-cancerous tissue to find out the rate of miR-183-5p expression, brought the finding that this miRNA is expressed significantly 4.31-fold higher in the PTC tissue $(t=4.487, d f=50, P T C$ Mean $\pm S D=-9.075 \pm 0.9741$, control Mean $\pm S D=-10.67 \pm 1.556, P$ value $<0.0001)$.

\section{miR-30d-5p}

As mentioned earlier, there is an inverse relationship between autophagy activity and miR-30d-5p [24, 31]. Our assessment on the rate of expression of miR-30d-5p in PTC and non-malignant tissue and comparing them with each other revealed that the level of this miRNA is 6.51 -fold decreased in the PTC tissue and this difference is illustrated in figure 4 (PTC Mean $\pm S D=-4.668 \pm 3.989$, control Mean $\pm S D=-2.128 \pm 1.906$, P-value $=0.0156)$.

Eventually the correlations of values of the variables is calculated and displayed in table 3.

\section{Discussion}


Papillary Thyroid Cancer is known as slowly growing tumors, predicting a favorable prognosis that yields a high survival rate [32]. Autophagy has been studied in various physiologic and pathophysiologic conditions including cancer. A vast amount of papers indicated FOXO1 as the main player of the FOXO signaling pathway (KEGGmap04068) that induces autophagy as a response to cell senescence [33]. FOXO1 mRNA reveals a 10.4 FPKM (Fragments Per Kilobase of transcript, per Million mapped reads) expression level in cancer bulk data that show increased expression in thyroid cancer compared to other types of malignancies [34]. A significant downregulation in miR-30d-5p levels (6.51 fold), which targets too much mRNA that may support functional activation of diverse cellular pathways in PTC patients. Recent studies indicate miR-30d-5p as Autophagy general regulator agent [23,30]. Our data indicate a 2.66 fold decrease in FOX01 mRNA comparing to adjacent normal tissue, which could be considered as autophagy molecular players.

Previous investigations on miR-182-5p and miR-183-5p expression levels have been done in malignant tissues other than thyroid and display an upregulation that is almost correlated with high proliferation and invasion of the tumor [28]. In our study, miR-182-5p and miR-183-5p display 1.73 and 4.31 fold change upregulation respectively, considering that these two miRNAs targeted mRNA in a more specific manner [29], the correlation between these two miRNAs have been demonstrated in previous works and FOX01 is shown as their main target. However, FOXO1 downregulation as apparent target of these miRNAs may be justified by this interaction $[29,33]$.

These data are compatible with the accepted hypothesis that autophagy is active in PTC tumors. Cell cycle machinery hyperactivation-induced cellular senescence is overcome by autophagy $[35,36]$.

Large-scale genomic studies indicate that BRAF600E mutation with a $58 \%$ rate is accepted as the most prevalent genetic variation in PTC. Although BRAF600E mutation is prevalent in PTC, it seems that RasRaf-MEK-ERK pathway overactivation is successfully sensed by cell cycle regulatory system and limitedly causes proliferation, shown by minimal Ki67 expression [34, 37].

Recent attempts in integrative modeling of DNA-damage effect on cell cycle display that the onset of the senescence occurs by the function of ATM (ataxia telangiectasia mutated) and ATR (ATM and Rad3related) members of DNA damage checkpoint of $\mathrm{G} 1 / \mathrm{S}$ and $\mathrm{G} 2$ cell cycle arrest [38, 39]. Persistent arrest in the G1/S and $\mathrm{G} 2$ phase activates a series of compensating mechanisms for cell survival. Altogether, cells that undergo constant senescence have a few types of machinery to escape this undesired condition. Autophagy is accepted as a major mechanism for survival. This potent proliferation stimulus must be compensated by another pathway, our results indicate that autophagy is the fittest candidate as a compensating pathway that progresses following the initiation of cell cycle arrest.

Despite surgical interventions, therapeutic strategies in PTC mainly are built on oral radioactive iodine consumption that induces DNA damage and consequent DNA double-strand break accumulation leads to aberrant apoptosis by overwhelming the compensating mechanisms [40]. 
MicroRNA signatures in human cancers are vastly investigated in recent years, but it must be considered that every single miRNA has multiple targets that little is known about the exact inhibitory effect of each miRNA on a definite target[41, 42]. But as confirmed by bulk data analysis via artificial intelligence algorithms and meta-analysis studies, many cancers display special variations in some miRNA clusters that sometimes could be generalized to individual pathways that may sign in a given cancer type $[41,43$, 44].

In this study, we detected a 6.51 -fold of down-regulation in miR-30d-5p levels that regulates multiple mRNAs in autophagy pathway with relative up-regulation in miR-182-5p and miR-183-5p levels which target FOXO1 mRNA by high level of specificity and down-regulation in FOXO1 -the canonical member of FOXO pathway (KEGGmap04068). These findings confirm our hypothesis that autophagy is an effective mechanism in PTC tumors and may be a clue for the presence of other miRNA and mRNA profiles that could predict the molecular status of PTC tumors or autophagy itself.

The dynamic behavior of the FOXO pathway indicates that many studies could be based on this context to reveal the actual importance of autophagy in PTC and other malignancies that face the cellular senescence.

Two major limitations can be mentioned in our study: First, the small size of tumor and normal tissue samples ( 40 for each) that in samples with a larger size, the distribution of data determination are more accurate and reliable. Second, the lack of access to the patients to determine the miRNA levels in their serum and to define the prognostic factors like overall survival to identify the possible impact of these biomarkers on post-surgical prognosis. These limitations may motivate the researchers to design studies to determine these parameters.

\section{Declarations}

\section{Funding}

This work was supported by "Hematology and Oncology Research Center, Tabriz University of Medical Sciences". The received funds were solely consumed for the collection of the patients and laboratory assay.

\section{Conflict of interest}

The authors declare that they have no competing interests.

\section{Availability of data and material}

The datasets used and/or analyzed during the current study are available from the corresponding author on reasonable request. 


\section{Code availability}

Not applicable

\section{Authors' contributions}

All authors contributed equally in this work.

\section{Ethics approval}

This study was approved by our local institutional review board (IRB) (approval No.IR.TBZMED.REC.1398.1262), written informed consent was obtained from all participants.

\section{Consent to participate}

The medical ethics committee of Tabriz faculty of medicine approved our proposal on the behalf of participants due to their unavailability at the moment of study.

\section{Consent for publication}

Not applicable

\section{Acknowledgements}

None.

\section{References}

1. Siegel RL, Miller KD, Fuchs HE, Jemal A (2021) Cancer Statistics. CA Cancer J Clin 71:7-33

2. Milano AF (2018) Thyroid Cancer: 20-Year Comparative Mortality and Survival Analysis of Six Thyroid Cancer Histologic Subtypes by Age, Sex, Race, Stage, Cohort Entry Time-Period and Disease Duration (SEER ${ }^{\star S t a t}$ 8.3.2) A Systematic Review of 145,457 Cases for Diagnosis Years 1993-2013. J Insur Med 47:143-158

3. Aschebrook-Kilfoy B, Ward MH, Sabra MM, Devesa SS (2011) Thyroid cancer incidence patterns in the United States by histologic type, 1992-2006, Thyroid 21, 125 - 34

4. Sanabria A, Kowalski LP, Shah JP, Nixon IJ, Angelos P, Williams MD, Rinaldo A, Ferlito A (2018) Growing incidence of thyroid carcinoma in recent years: Factors underlying overdiagnosis. Head Neck 40:855-866

5. Kitahara CM, Sosa JA (2020) Understanding the ever-changing incidence of thyroid cancer. Nat Rev Endocrinol 16:617-618

6. Ahn HS, Na DG, Baek JH, Sung JY, Kim JH (2019) False negative rate of fine-needle aspiration in thyroid nodules: impact of nodule size and ultrasound pattern. Head Neck 41:967-973 
7. Yang Z, Wei X, Pan Y, Xu J, Si Y, Min Z, Yu B (2021) A new risk factor indicator for papillary thyroid cancer based on immune infiltration. Cell Death Dis 12:51

8. Melany M, Chen S (2017) Thyroid Cancer: Ultrasound Imaging and Fine-Needle Aspiration Biopsy. Endocrinol Metab Clin North Am 46:691-711

9. Dom G, Frank S, Floor S, Kehagias P, Libert F, Hoang C, Andry G, Spinette A, Craciun L, de Saint Aubin $\mathrm{N}$, Tresallet C, Tissier F, Savagner F, Majjaj S, Gutierrez-Roelens I, Marbaix E, Dumont JE, Maenhaut C (2017) Thyroid follicular adenomas and carcinomas: molecular profiling provides evidence for a continuous evolution. Oncotarget 9:10343-10359

10. Onorati AV, Dyczynski M, Ojha R, Amaravadi RK (2018) Targeting autophagy in cancer. Cancer 124:3307-3318

11. Zheng K, He Z, Kitazato K, Wang Y (2019) Selective Autophagy Regulates Cell Cycle in Cancer Therapy. Theranostics 9:104-125

12. Yun CW, Lee SH (2018) The Roles of Autophagy in Cancer. Int J Mol Sci 19:3466

13. Zhi X, Zhong Q (2015) Autophagy in cancer. F1000prime reports 7:18-18

14. Morani F, Titone R, Pagano L, Galetto A, Alabiso O, Aimaretti G, Isidoro C (2014) Autophagy and thyroid carcinogenesis: genetic and epigenetic links. Endocr Relat Cancer 21:R13-R29

15. Netea-Maier RT, Klück V, Plantinga TS, Smit JWA (2015) Autophagy in thyroid cancer: present knowledge and future perspectives. Front Endocrinol 6:22-22

16. Zhao Y, Yang J, Liao W, Liu X, Zhang H, Wang S, Wang D, Feng J, Yu L, Zhu WG (2010) Cytosolic FoxO1 is essential for the induction of autophagy and tumour suppressor activity. Nat Cell Biol 12:665-675

17. Eijkelenboom A, Burgering BM (2013) FOXOs: signalling integrators for homeostasis maintenance. Nat Rev Mol Cell Biol 14:83-97

18. Weidinger C, Krause K, Fuhrer D (2011) Novel insights into FOXOlogy: FOXOs and their putative role in thyroid carcinogenesis. Expert Rev Endocrinol Metab 6:63-69

19. Parpart S, Wang XW (2013) microRNA Regulation and Its Consequences in Cancer. Curr Pathobiol Rep 1:71-79

20. Chruścik A, Lam AK (2015) Clinical pathological impacts of microRNAs in papillary thyroid carcinoma: A crucial review. Exp Mol Pathol 99:393-398

21. Peng Y, Croce CM (2016) The role of MicroRNAs in human cancer. Signal Transduct Target Ther $1: 15004$

22. Myatt SS, Wang J, Monteiro LJ, Christian M, Ho K-K, Fusi L, Dina RE, Brosens JJ, Ghaem-Maghami S, Lam EWF (2010) Definition of microRNAs that repress expression of the tumor suppressor gene FOX01 in endometrial cancer. Cancer research 70:367-377

23. Li N, Kaur S, Greshock J, Lassus H, Zhong X, Wang Y, Leminen A, Shao Z, Hu X, Liang S, Katsaros D, Huang Q, Bützow R, Weber BL, Coukos G, Zhang L (2012) A combined array-based comparative 
genomic hybridization and functional library screening approach identifies mir-30d as an oncomir in cancer. Cancer Res 72:154-164

24. Yang X, Zhong X, Tanyi JL, Shen J, Xu C, Gao P, Zheng TM, DeMichele A, Zhang L (2013) mir-30d Regulates multiple genes in the autophagy pathway and impairs autophagy process in human cancer cells. Biochem Biophys Res Commun 431:617-622

25. Yu S, Liu Y, Wang J, Guo Z, Zhang Q, Yu F, Zhang Y, Huang K, Li Y, Song E, Zheng XL, Xiao H (2012) Circulating microRNA profiles as potential biomarkers for diagnosis of papillary thyroid carcinoma. $J$ Clin Endocrinol Metab 97:2084-2092

26. Livak KJ, Schmittgen TD (2001) Analysis of relative gene expression data using real-time quantitative PCR and the 2(-Delta Delta C(T)) Method, Methods 25, 402-8

27. Zhou J, Liao W, Yang J, Ma K, Li X, Wang Y, Wang D, Wang L, Zhang Y, Yin Y, Zhao Y, Zhu W-G (2012) FOXO3 induces FOX01-dependent autophagy by activating the AKT1 signaling pathway. Autophagy 8:1712-1723

28. Suzuki R, Amatya VJ, Kushitani K, Kai Y, Kambara T, Takeshima Y (2018) miR-182 and miR-183 Promote Cell Proliferation and Invasion by Targeting FOXO1 in Mesothelioma. Frontiers in oncology 8:446-446

29. Vergoulis T, Vlachos IS, Alexiou P, Georgakilas G, Maragkakis M, Reczko M, Gerangelos S, Koziris N, Dalamagas T, Hatzigeorgiou AG (2012) TarBase 6.0: capturing the exponential growth of miRNA targets with experimental support. Nucleic Acids Res 40:D222-D229

30. Zhang L, Quan H, Wang S, Li X, Che X (2015) MiR-183 promotes growth of non-small cell lung cancer cells through FoxO1 inhibition. Tumour Biol 36:8121-8126

31. Liang L, Yang Z, Deng Q, Jiang Y, Cheng Y, Sun Y, Li L (2021) miR-30d-5p suppresses proliferation and autophagy by targeting ATG5 in renal cell carcinoma. FEBS open bio 11:529-540

32. Jonklaas J, Nogueras-Gonzalez G, Munsell M, Litofsky D, Ain KB, Bigos ST, Brierley JD, Cooper DS, Haugen BR, Ladenson PW, Magner J, Robbins J, Ross DS, Skarulis MC, Steward DL, Maxon HR, Sherman SI (2012) The impact of age and gender on papillary thyroid cancer survival. J Clin Endocrinol Metab 97:E878-E887

33. Wu L, Grigoryan AV, Li Y, Hao B, Pagano M, Cardozo TJ (2012) Specific small molecule inhibitors of Skp2-mediated p27 degradation. Chem Biol 19:1515-1524

34. Uhlen M, Zhang C, Lee S, Sjöstedt E, Fagerberg L, Bidkhori G, Benfeitas R, Arif M, Liu Z, Edfors F, Sanli K, von Feilitzen K, Oksvold P, Lundberg E, Hober S, Nilsson P, Mattsson J, Schwenk JM, Brunnström H, Glimelius B, Sjöblom T, Edqvist PH, Djureinovic D, Micke P, Lindskog C, Mardinoglu A, Ponten F (2017) A pathology atlas of the human cancer transcriptome, Science 357

35. Chalmers ZR, Connelly CF, Fabrizio D, Gay L, Ali SM, Ennis R, Schrock A, Campbell B, Shlien A, Chmielecki J, Huang F, He Y, Sun J, Tabori U, Kennedy M, Lieber DS, Roels S, White J, Otto GA, Ross JS, Garraway L, Miller VA, Stephens PJ, Frampton GM (2017) Analysis of 100,000 human cancer genomes reveals the landscape of tumor mutational burden. Genome Med 9:34 
36. Campbell BB, Light N, Fabrizio D, Zatzman M, Fuligni F, de Borja R, Davidson S, Edwards M, Elvin JA, Hodel KP, Zahurancik WJ, Suo Z, Lipman T, Wimmer K, Kratz CP, Bowers DC, Laetsch TW, Dunn GP, Johanns TM, Grimmer MR, Smirnov IV, Larouche V, Samuel D, Bronsema A, Osborn M, Stearns D, Raman P, Cole KA, Storm PB, Yalon M, Opocher E, Mason G, Thomas GA, Sabel M, George B, Ziegler DS, Lindhorst S, Issai VM, Constantini S, Toledano H, Elhasid R, Farah R, Dvir R, Dirks P, Huang A, Galati MA, Chung J, Ramaswamy V, Irwin MS, Aronson M, Durno C, Taylor MD, Rechavi G, Maris JM, Bouffet E, Hawkins C, Costello JF, Meyn MS, Pursell ZF, Malkin D, U. Tabori and A. Shlien (2017) Comprehensive Analysis of Hypermutation in Human Cancer, Cel/ 171, 1042-1056.e10

37. 37

38. Mombach JC, Bugs CA, Chaouiya C (2014) Modelling the onset of senescence at the G1/S cell cycle checkpoint. BMC Genom 15(Suppl 7):S7

39. Chao HX, Fakhreddin RI, Shimerov HK, Kedziora KM, Kumar RJ, Perez J, Limas JC, Grant GD, Cook JG, Gupta GP, Purvis JE (2019) Evidence that the human cell cycle is a series of uncoupled, memoryless phases. Molecular systems biology 15:e8604-e8604

40. Yogosawa S, Yoshida K (2018) Tumor suppressive role for kinases phosphorylating p53 in DNA damage-induced apoptosis. Cancer Sci 109:3376-3382

41. Calin GA, Croce CM (2006) MicroRNA signatures in human cancers. Nat Rev Cancer 6:857-866

42. Lv Y, Duanmu J, Fu X, Li T, Jiang Q (2020) Identifying a new microRNA signature as a prognostic biomarker in colon cancer. PLoS One 15:e0228575

43. Oztemur Islakoglu Y, Noyan S, Aydos A, Gur B Dedeoglu (2018) Meta-microRNA Biomarker Signatures to Classify Breast Cancer Subtypes. Omics 22:709-716

44. Søkilde R, Persson H, Ehinger A, Pirona AC, Fernö M, Hegardt C, Larsson C, Loman N, Malmberg M, Rydén L, Saal L, Borg Å, Vallon-Christerson J, Rovira C (2019) Refinement of breast cancer molecular classification by miRNA expression profiles. BMC Genom 20:503

\section{Tables}

Table 1. Patient information and tumor characteristics 


\begin{tabular}{|llll|}
\hline Parameters & & Frequency & Percent \\
\hline \multirow{2}{*}{ Involved Lobe } & Female & 21 & $52.5 \%$ \\
\cline { 2 - 4 } & Male & 19 & $47.5 \%$ \\
\cline { 2 - 4 } & Right & 20 & $50.0 \%$ \\
\cline { 2 - 4 } & Left & 16 & $40.0 \%$ \\
\hline Tumor/Nodule & Both & 4 & $10 \%$ \\
\cline { 2 - 4 } size & Aelow $2 \mathrm{~cm}$ & 21 & $52.5 \%$ \\
\hline Capsular & Yes & 6 & $47.5 \%$ \\
\cline { 2 - 4 } Involvement & No & 34 & $85 \%$ \\
\cline { 2 - 4 } & & 19 & $15 \%$ \\
\hline
\end{tabular}

Table 2. FOXO1 and selected miRNAs' alterations in tumoral tissue in comparison to normal adjacent tissue

\begin{tabular}{|c|c|c|c|c|}
\hline & & Mean $\pm S D$ & Fold change tumor tissue & P-value \\
\hline \multirow[t]{4}{*}{ F0X01 } & PTC & $-0.3767 \pm$ & $2.66 \mathrm{~d}$ & $<0.0001$ \\
\hline & & 1.36 & & \\
\hline & Control & $1.418 \pm$ & & \\
\hline & & 1.373 & & \\
\hline \multirow[t]{4}{*}{ miR-182-5p } & PTC & $-9.136 \pm$ & $1.73 \tilde{n}$ & 0.007 \\
\hline & & 1.201 & & \\
\hline & Control & $-10.14 \pm$ & & \\
\hline & & 1.414 & & \\
\hline \multirow[t]{4}{*}{ miR-183-5p } & PTC & $-9.075 \pm$ & $4.31 \tilde{n}$ & $<0.0001$ \\
\hline & & 0.9741 & & \\
\hline & Control & $-10.67 \pm$ & & \\
\hline & & 1.556 & & \\
\hline \multirow[t]{4}{*}{ miR-30d-5p } & PTC & $-4.668 \pm$ & 6.51 ò & 0.0156 \\
\hline & & 3.989 & & \\
\hline & Control & $-2.128 \pm$ & & \\
\hline & & 1.906 & & \\
\hline
\end{tabular}


Table 3. Correlation of the values based on delta

\begin{tabular}{|llll|}
\hline & FOXO1 & miR-182-5p & miR183-5p \\
\hline FOX01 & 1.000 & 0.140 & -0.096 \\
\hline miR-182-5p & 0.140 & 1.000 & 0.261 \\
miR-183-5p & -0.096 & 0.261 & 1.000 \\
\hline
\end{tabular}

Figures
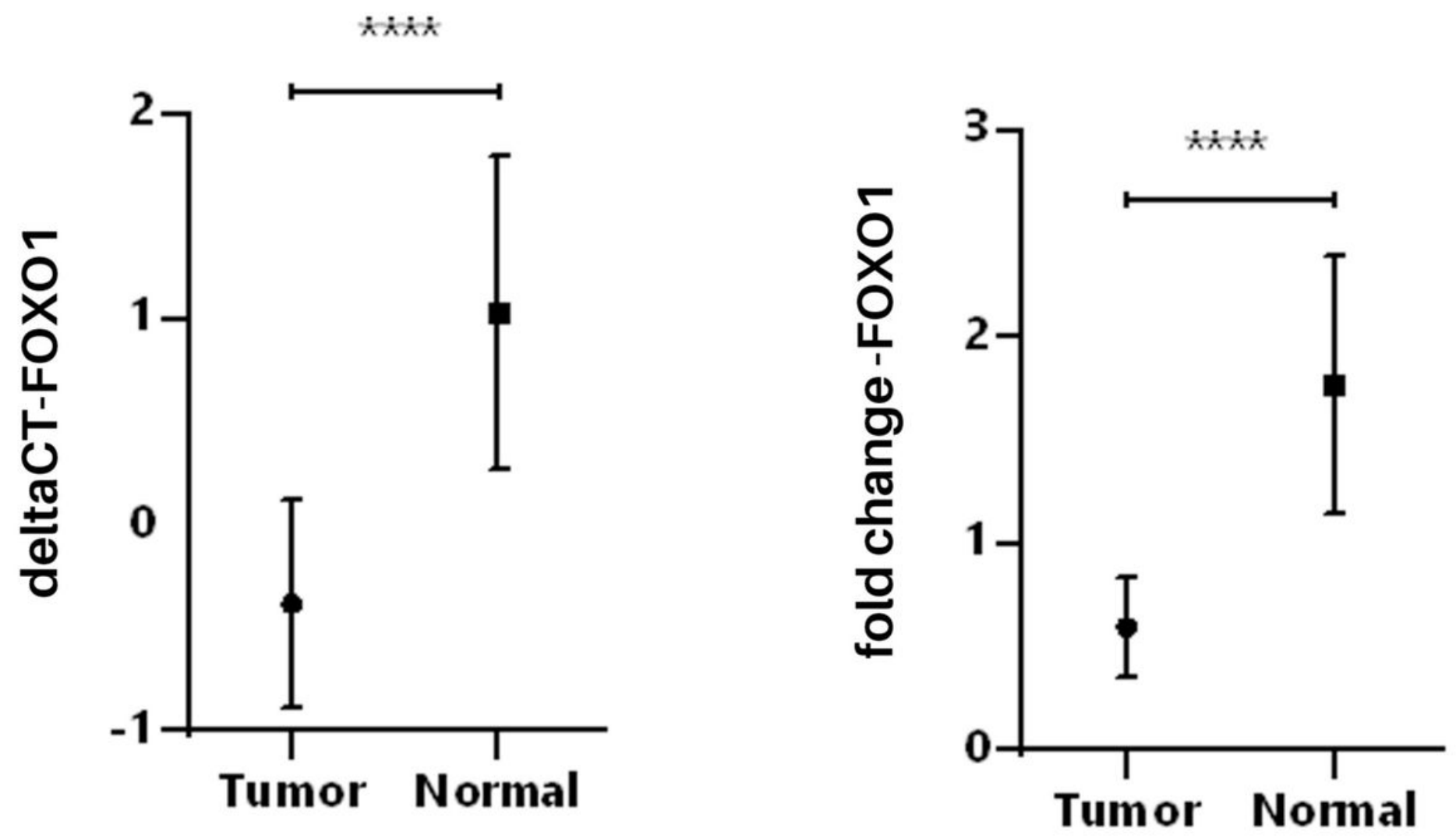

Figure 1

Comparison of expression levels of FOXO1 in PTC and adjacent non-cancerous tissue reveals a 2.66-fold decrease in PTC tissue with the p-value of $<0.0001$ 

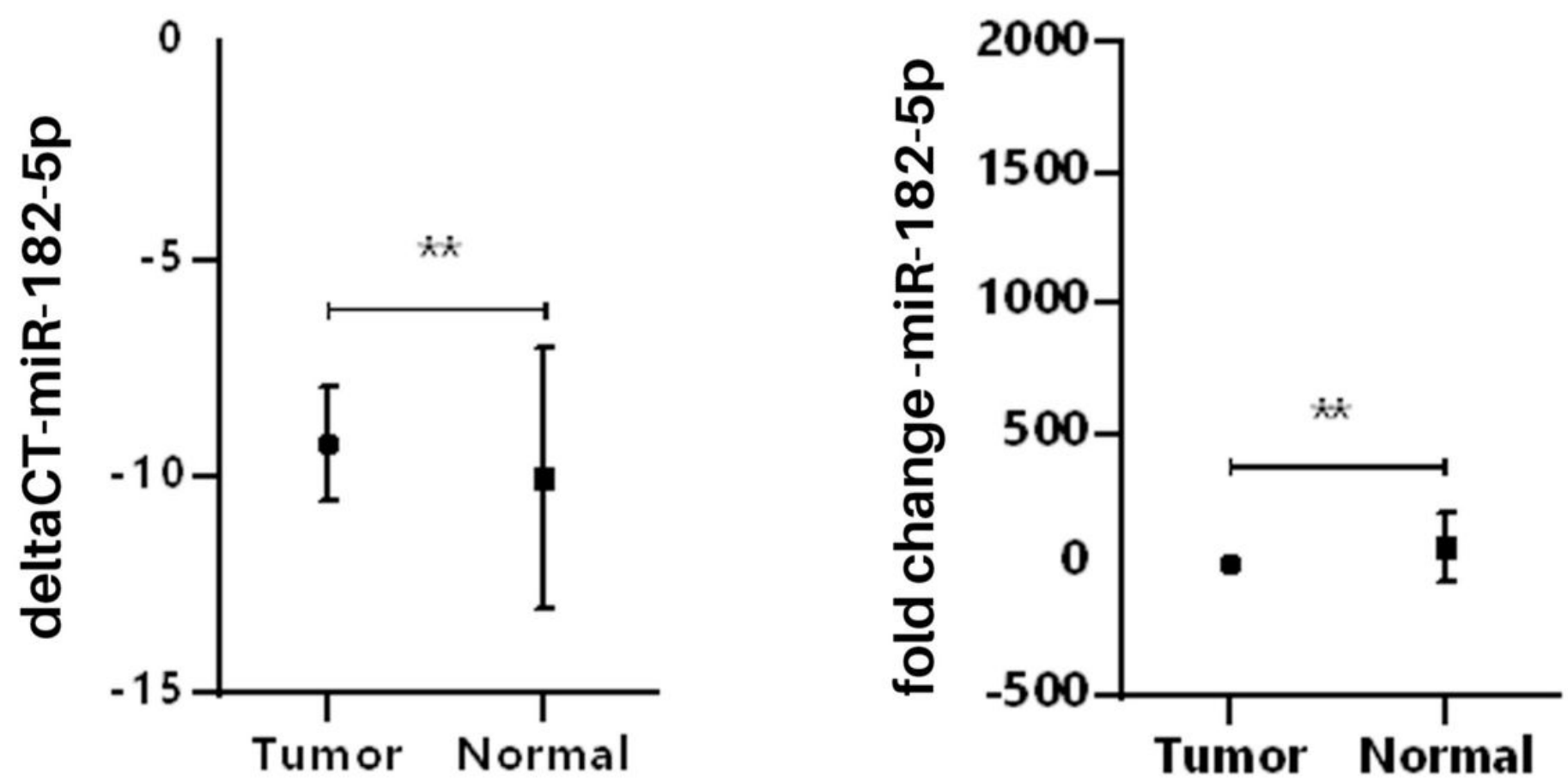

Figure 2

Comparison of expression levels of miR-182-5p in PTC and adjacent non-cancerous tissue reveals a 1.73increase in the PTC tissue with the p-value of 0.007 

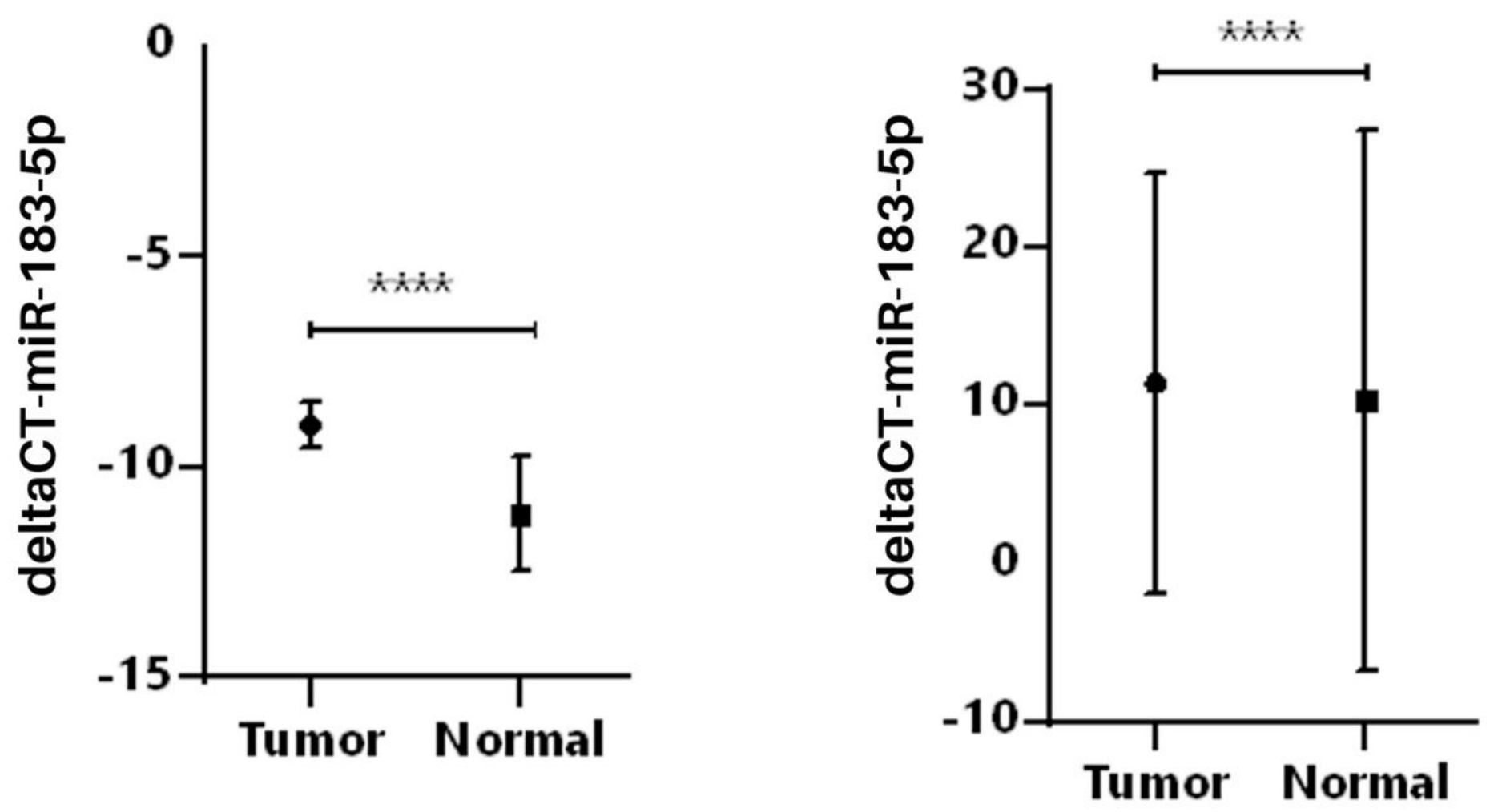

Figure 3

Comparison of expression levels of miR-183-5p in PTC and adjacent non-cancerous tissue reveals a 4.31fold increase in the PTC tissue with the p-value of $<0.0001$ 

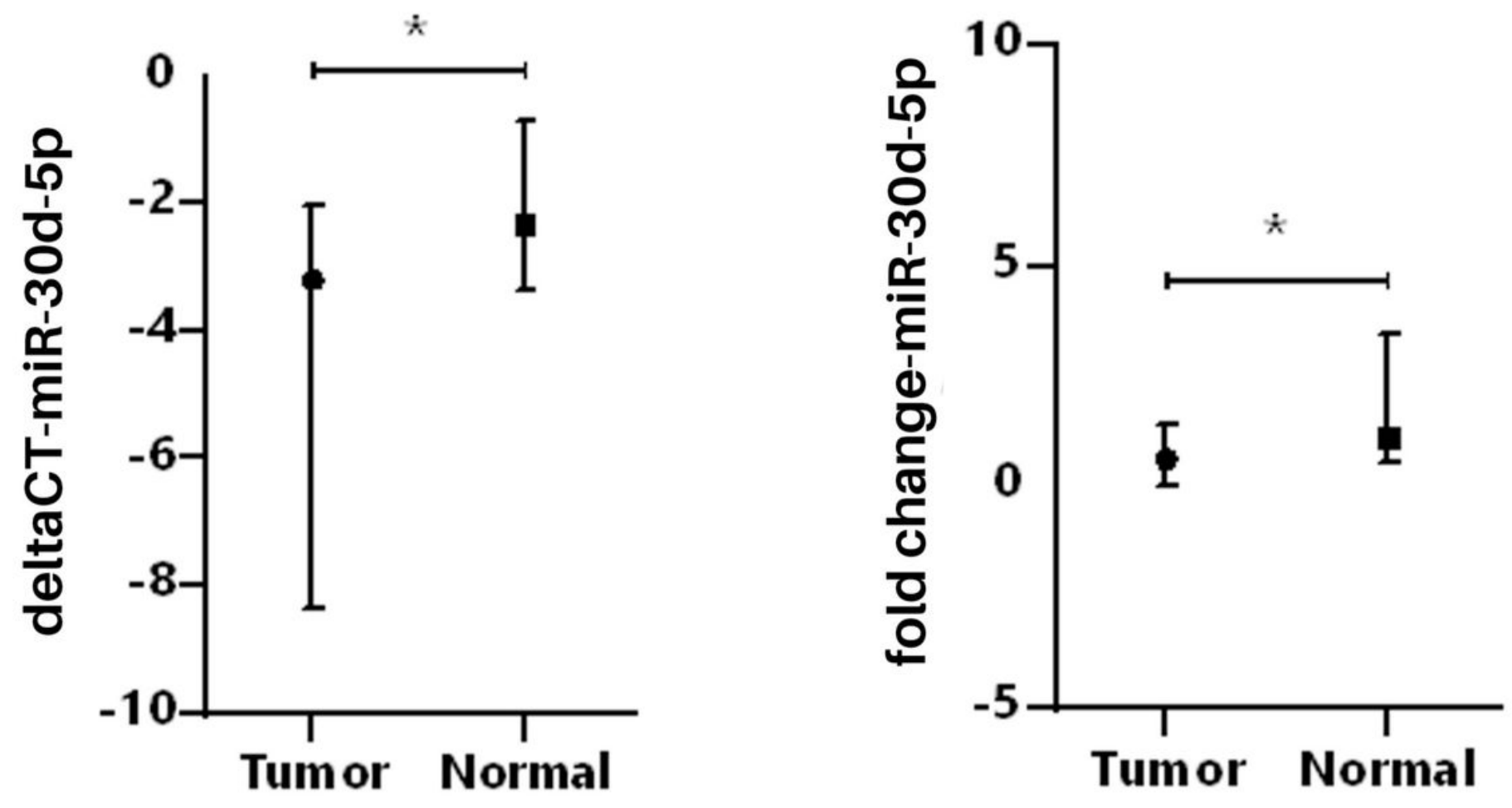

Figure 4

Comparison of expression levels of miR-30d-5p in PTC and adjacent non-cancerous tissue reveals a 6.51fold decrease in the PTC tissue with the p-value of 0.0156 